\title{
Cost and Potential of Monolithic CIGS Photovoltaic Modules
}

IEEE Photovoltaic Specialists Conference, New Orleans

Kelsey A. W. Horowitz and Michael Woodhouse

June 17, 2015 


\section{Analysis Disclaimer}

\section{DISCLAIMER AGREEMENT}

These manufacturing cost model results ("Data") are provided by the National Renewable Energy Laboratory ("NREL"), which is operated by the Alliance for Sustainable Energy LLC ("Alliance") for the U.S. Department of Energy (the "DOE").

It is recognized that disclosure of these Data is provided under the following conditions and warnings: (1) these Data have been prepared for reference purposes only; (2) these Data consist of forecasts, estimates or assumptions made on a best-efforts basis, based upon present expectations; and (3) these Data were prepared with existing information and are subject to change without notice.

The names DOE/NREL/ALLIANCE shall not be used in any representation, advertising, publicity or other manner whatsoever to endorse or promote any entity that adopts or uses these Data. DOE/NREL/ALLIANCE shall not provide any support, consulting, training or assistance of any kind with regard to the use of these Data or any updates, revisions or new versions of these Data.

YOU AGREE TO INDEMNIFY DOE/NREL/ALLIANCE, AND ITS AFFILIATES, OFFICERS, AGENTS, AND EMPLOYEES AGAINST ANY CLAIM OR DEMAND, INCLUDING REASONABLE ATTORNEYS' FEES, RELATED TO YOUR USE, RELIANCE, OR ADOPTION OF THESE DATA FOR ANY PURPOSE WHATSOEVER. THESE DATA ARE PROVIDED BY DOE/NREL/ALLIANCE "AS IS" AND ANY EXPRESS OR IMPLIED WARRANTIES, INCLUDING BUT NOT LIMITED TO, THE IMPLIED WARRANTIES OF MERCHANTABILITY AND FITNESS FOR A PARTICULAR PURPOSE ARE EXPRESSLY DISCLAIMED. IN NO EVENT SHALL DOE/NREL/ALLIANCE BE LIABLE FOR ANY SPECIAL, INDIRECT OR CONSEQUENTIAL DAMAGES OR ANY DAMAGES WHATSOEVER, INCLUDING BUT NOT LIMITED TO CLAIMS ASSOCIATED WITH THE LOSS OF DATA OR PROFITS, WHICH MAY RESULT FROM AN ACTION IN CONTRACT, NEGLIGENCE OR OTHER TORTIOUS CLAIM THAT ARISES OUT OF OR IN CONNECTION WITH THE USE OR PERFORMANCE OF THESE DATA. 


\section{Acknowledgments}

\section{Funding}

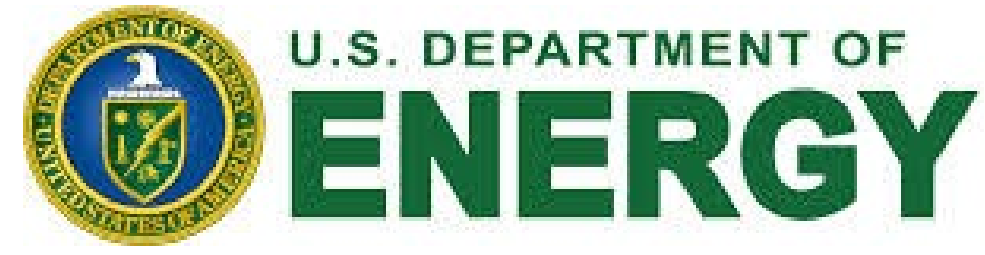

Energy Efficiency \& Renewable Energy

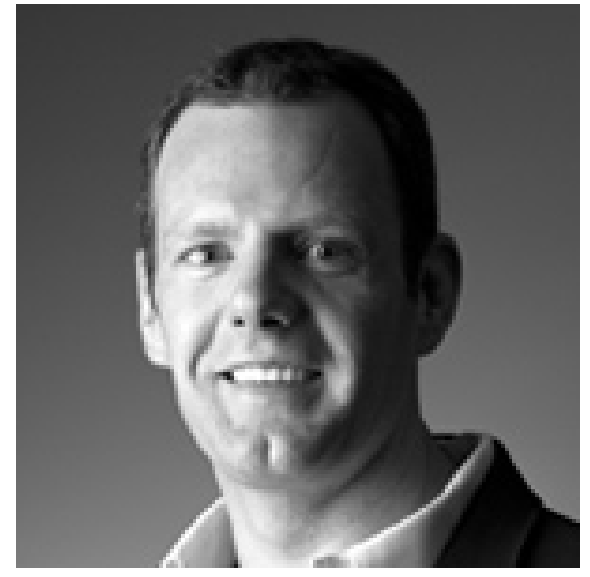

Dr. Michael Woodhouse Co-Author

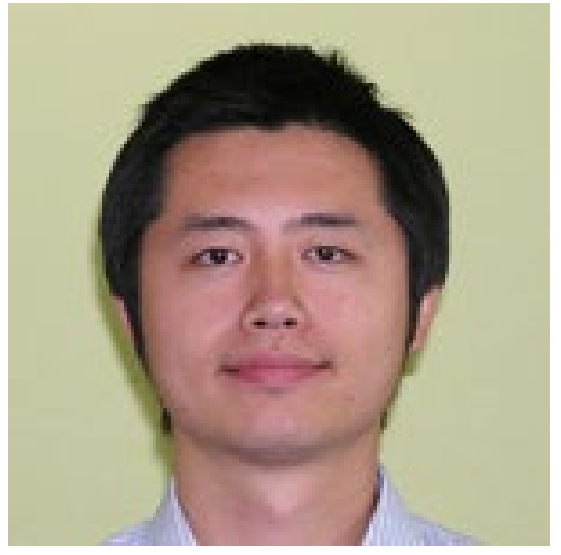

Ran Fu

Team Member, Systems Costs

NREL CIGS Team

All our collaborators in industry 


\section{Overview of Presentation}

- \$/W manufacturing costs and minimum sustainable price calculations for monolithic, glass-glass CIGS modules

- Sputtering plus sulfurization after selenization (SAS)

- Batch

- In-line rapid thermal process (RTP)

- Co-evaporation

- In-line, 1-stage process

- 3-stage process

- Cost reduction roadmap

- Levelized cost of energy (LCOE) for CIGS and standard c-Si technology

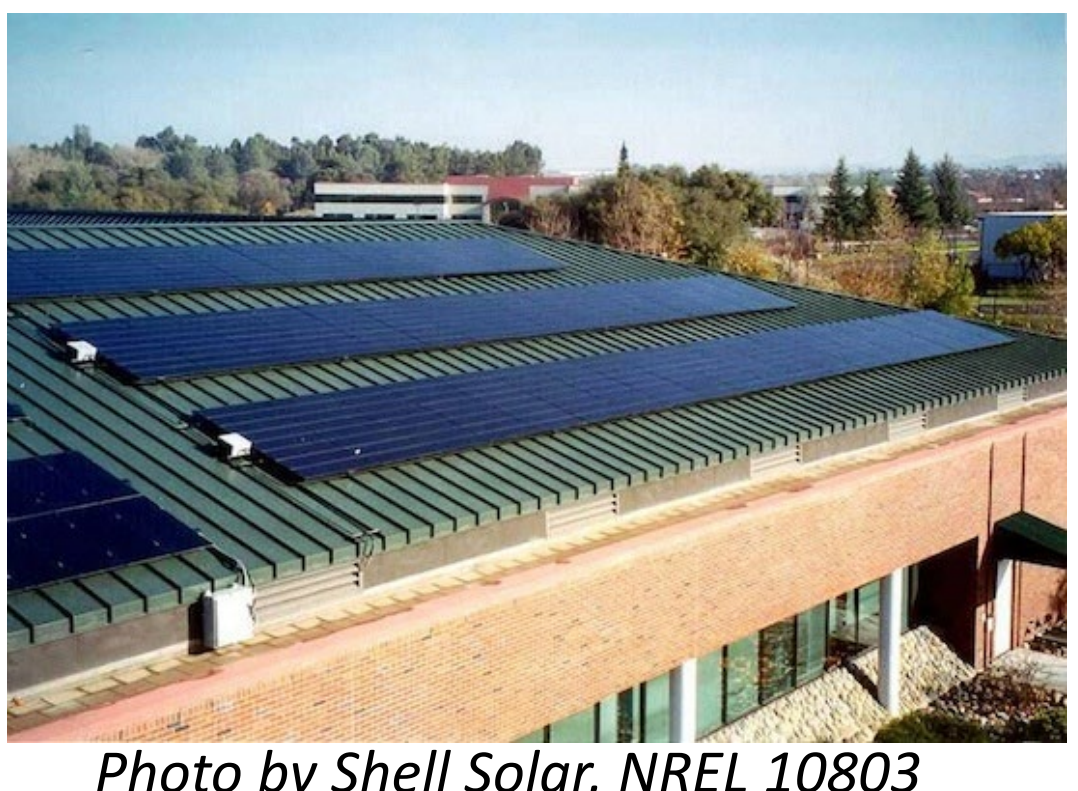




\section{Motivation}

CIGS technology has made great strides...

...but

- Efficiency

- 1970s: 4\% efficient cells

- 2015: 21.7\% record lab efficiency and $13-15 \%$ average production module efficiencies

- Production capacity

- Solar Frontier: GW-scale

- Stion, TMSC Solar, and Avancis: 100-200MW/year

- Improved stability and degradation.

- CIGS accounts for only 2-4\% of PV market shipments

- Vast majority of modules sold to the Japanese market

- Several CIGS start-ups have been acquired by Hanergy or have closed

- A lack of public CIGS companies means there is little publically available information on costs and prices. 


\section{Reference Case Assumptions}

Glass-glass monolithic module

- Low-iron tempered front glass (3.2 mm thick)

- Soda lime back glass (3.2mm thick)

$1.6 \mathrm{~m} \times 0.6 \mathrm{~m}$ substrate size

$1.5 \mu \mathrm{m}$ thick CIGS layer $250 \mathrm{~nm}$ thick Mo layer

$\mathrm{Ga} /(\mathrm{In}+\mathrm{Ga})=0.31$

$\mathrm{Cu} /(\mathrm{In}+\mathrm{Ga})=0.92$

Copper Indium Gallium Diselenide

(CIGS)

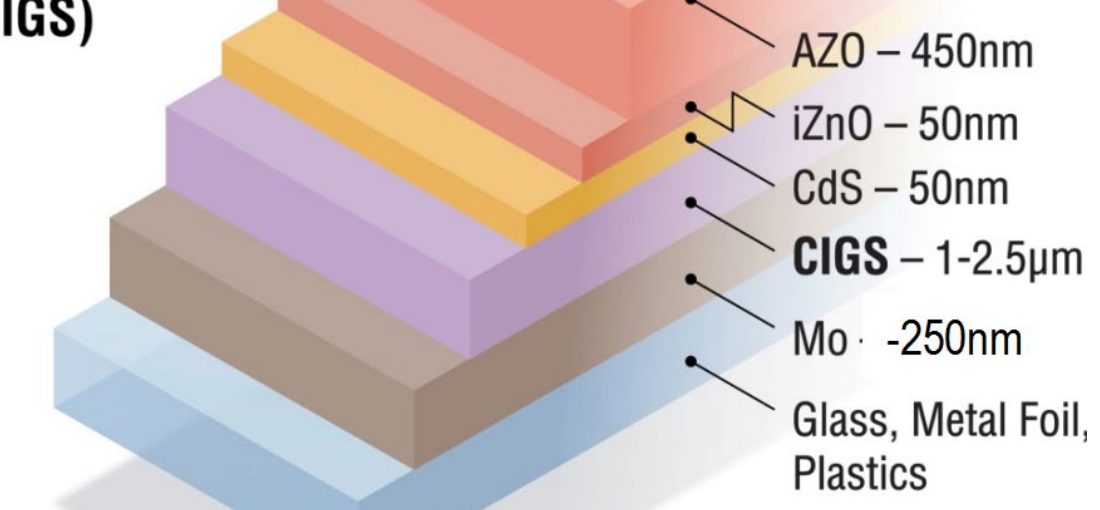

U.S. manufacturing

100MW/year production vuruı... 


\section{Method for Computing Manufacturing Cost}

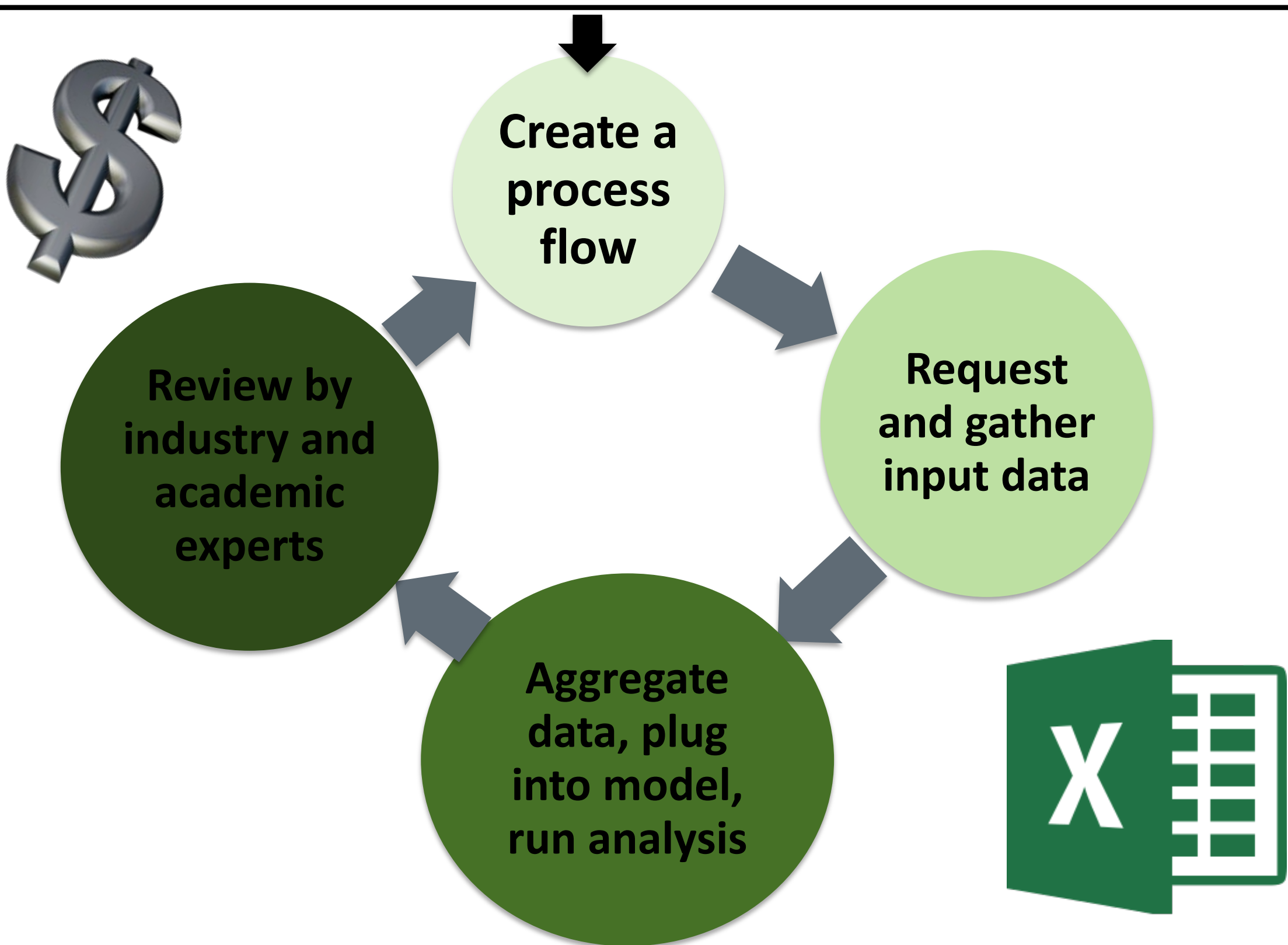




\section{Method for Computing Manufacturing Cost}

- Total cost of ownership for each step in the manufacturing process

- Materials

- Utilities

- Labor

- Depreciation (equipment and facilities/building)

- Maintenance

- Assume a largely automated manufacturing process

- 7-year and 15-year straight-line depreciation schedules for equipment and building, respectively. 


\section{Minimum Sustainable Price (MSP)}

- MSP: The price at which the net present value (NPV) of a 20-year project is equal to zero

- Minimum price necessary to generate a required rate of return

- We set the required rate of return to be the weighted average cost of capital (WACC)

$$
W A C C=E \cdot r_{e}+D \cdot r_{d} \cdot\left(1-r_{t}\right)
$$

- $E=\%$ equity, $D=\%$ debt, $r_{e}=$ cost of equity, $r_{d}=$ cost of debt, $r_{t}=$ corporate tax rate

- WACC $=14.5 \%$ calculated for the U.S. PV cell and module companies in 2015

- More information in: Fu, R.; James, T.; Woodhouse, M. (2015). “Economic Measurements of Polysilicon for the Photovoltaic Industry: Market Competition and Manufacturing Competitiveness." IEEE JPV 5; pp. 515-524. Accessed May 2015: http://ieeexplore.ieee.org/xpl/articleDetails.jsp?arnumber=7042229.

- Included in the NPV calculation:

- Manufacturing costs

- Overhead costs

- Research and development (R\&D) costs, assumed to be $8 \%$ of revenue

- Sales, general, and administrative (SG\&A) costs, assumed to be $4 \%$ of revenue

- Other costs (warranty, legal), assumed to be $2 \%$ of revenue

- Taxes, $28 \%$ effective federal corporate tax rate assumed

- Zero salvage value. 


\section{Manufacturing Process Flow}

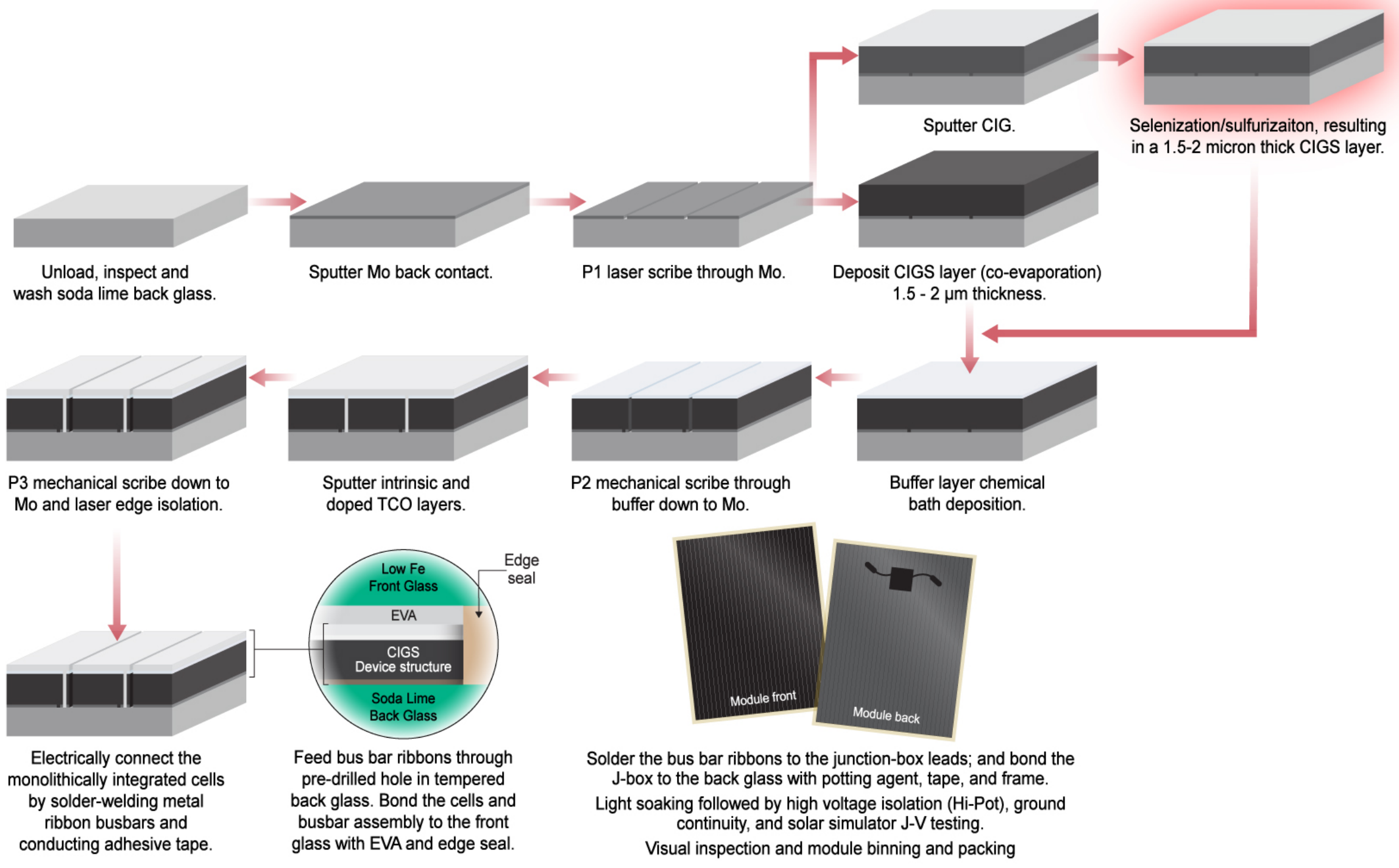




\section{CIGS Absorber Deposition Processes}

- Sputtering plus sulfurization after selenization (SAS)

- Batch: More mature, deployed in large-scale production today, higher efficiency, high yield Reference case

$\circ$ In-line RTP: Higher throughput if high yields can be achieved at scale, elemental Se

- Co-evaporation

- Not yet deployed in large-scale commercial production, earlier stage

- 3-stage process: Record cell efficiencies, low throughput, high capital cost

- 1-stage, in-line process: Higher throughput, lower efficiency than 3-stage. 


\section{Step-by-Step Manufacturing Costs}

Step-by-Step Manufacturing Costs for Sputtering + Batch SAS

U.S. Manufacturing, $100 \mathrm{MW} /$ year production, $1.6 \mathrm{~m} \times 0.6 \mathrm{~m}$ substrate

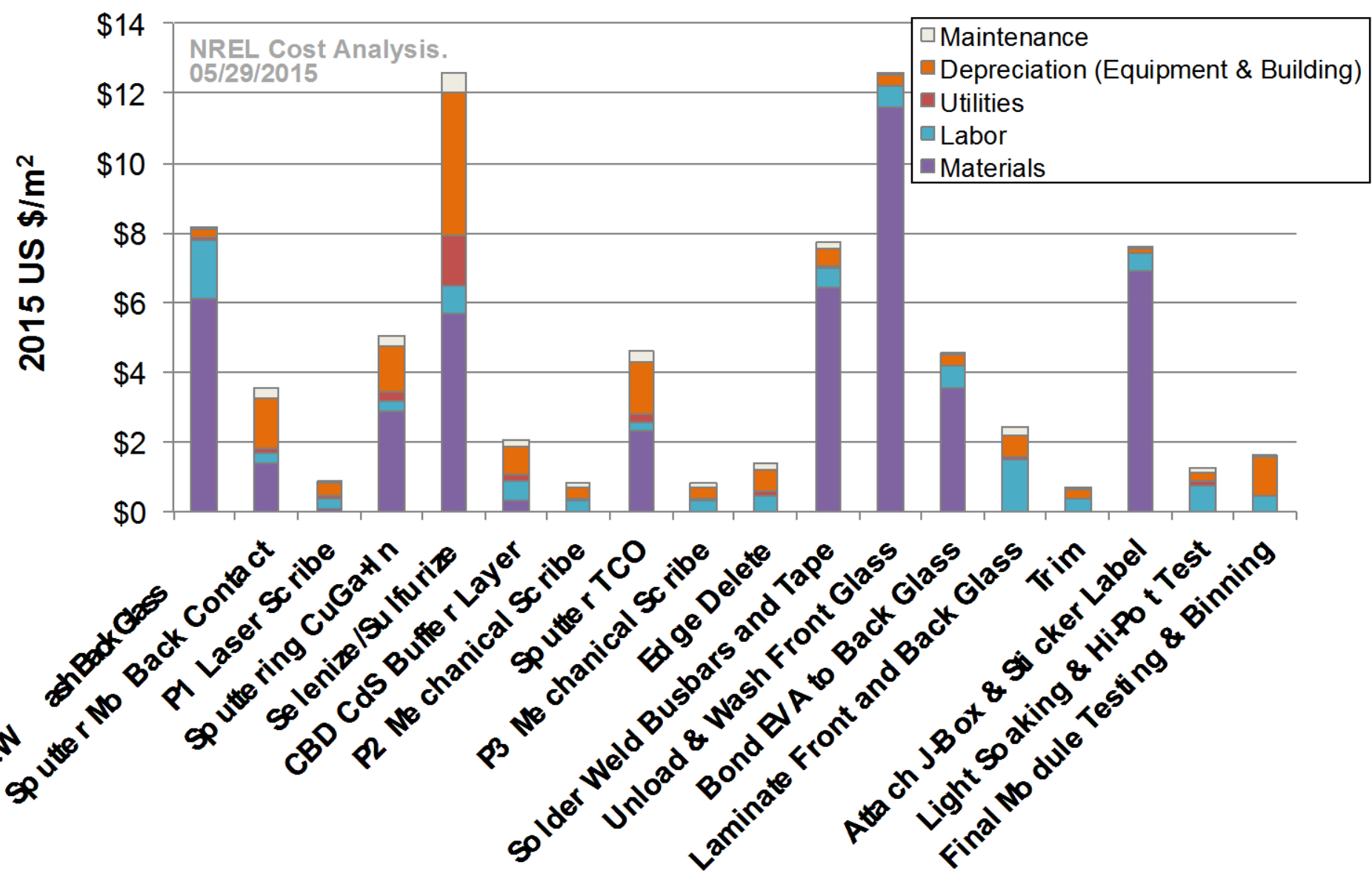

- Total module manufacturing cost: $\$ 78.22 / \mathrm{m}^{2}\left(\$ 0.59 / \mathrm{W}_{\mathrm{DC}}\right.$ at $14 \%$ efficiency)

- MSP: $\$ 0.72 / W_{\text {DC. }}$ 


\section{Manufacturing Cost Breakdown}
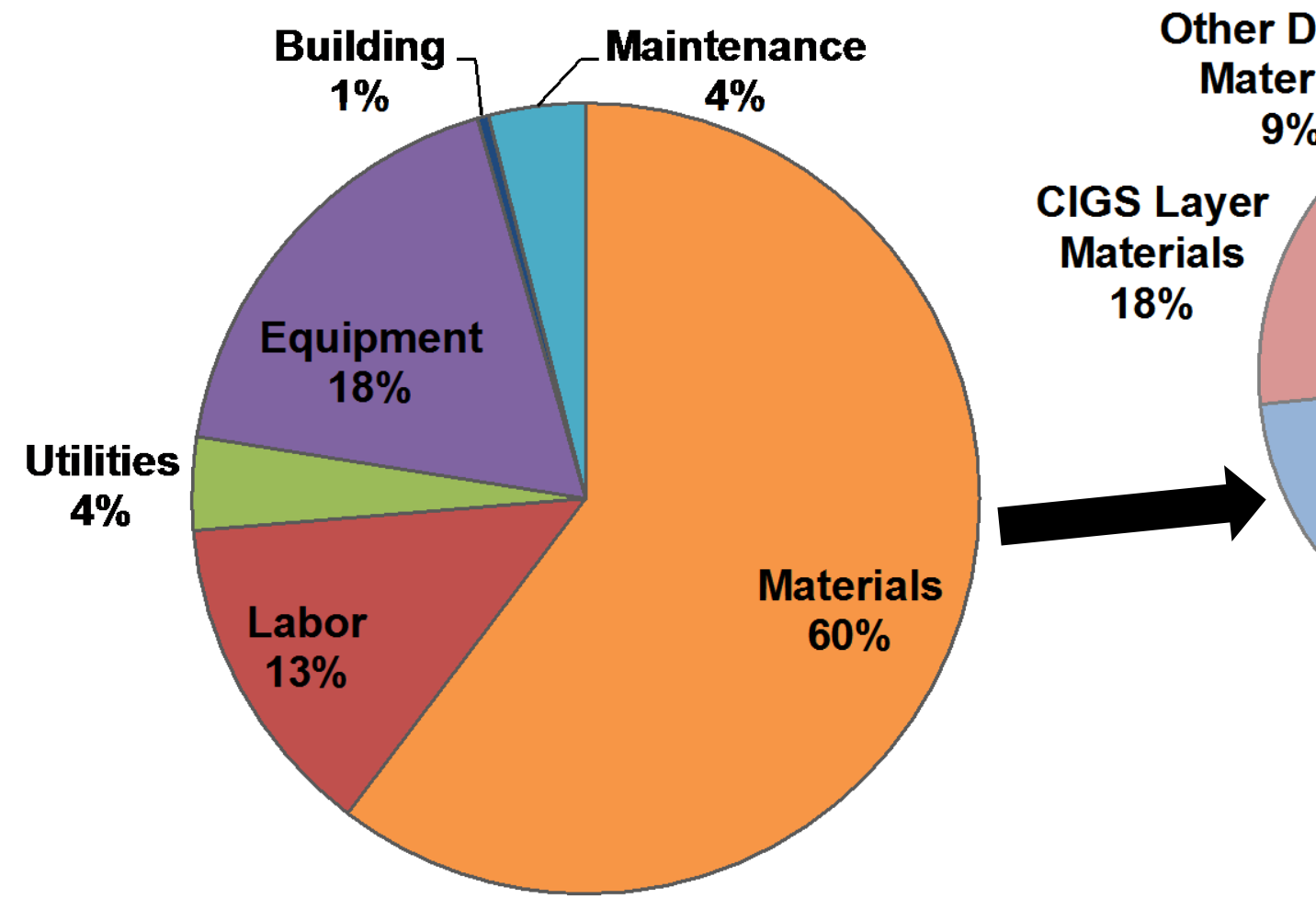

- Material costs dominate

- Balance of module materials are a significant cost driver

- The SAS step represents the largest device cost

- Exact breakdown will vary by region of manufacturing. 


\section{Comparison of Process Costs}

- This comparison assumes equal manufacturing scale and yields could be achieved. Additional efforts into the in-line RTP and co-evaporation processes are required to meet these goals.

- We find the 3-stage co-evaporation process to be more expensive than 1-stage co-evaporation or sputtering + batch SAS today.

- $16 \%$ efficiency for leading modules on commercial lines has been demonstrated both from sputtering + batch SAS and 1-stage, in-line co-evaporation. Which process will have a long-term efficiency advantage is unknown.

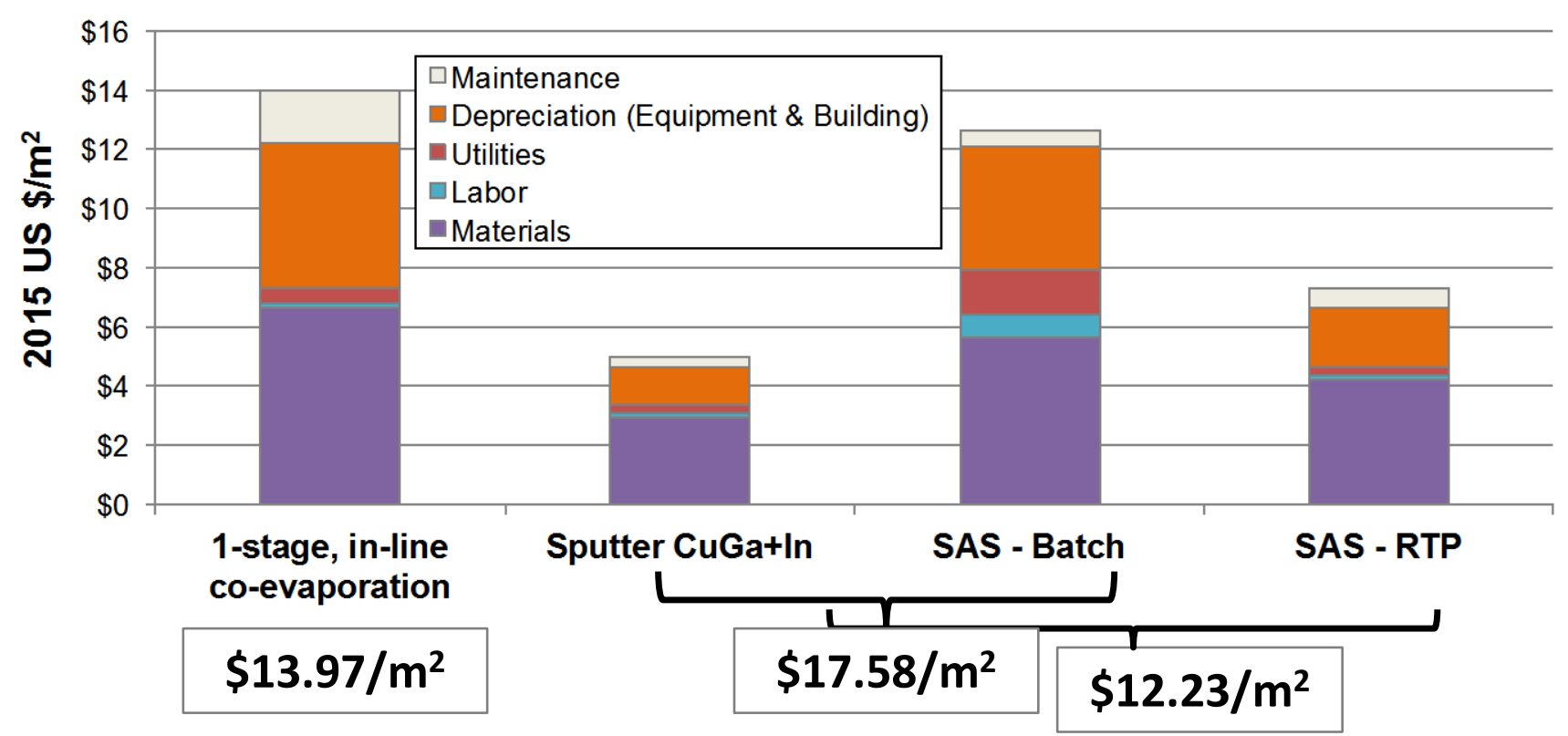




\section{Manufacturing Cost Reduction Roadmap}

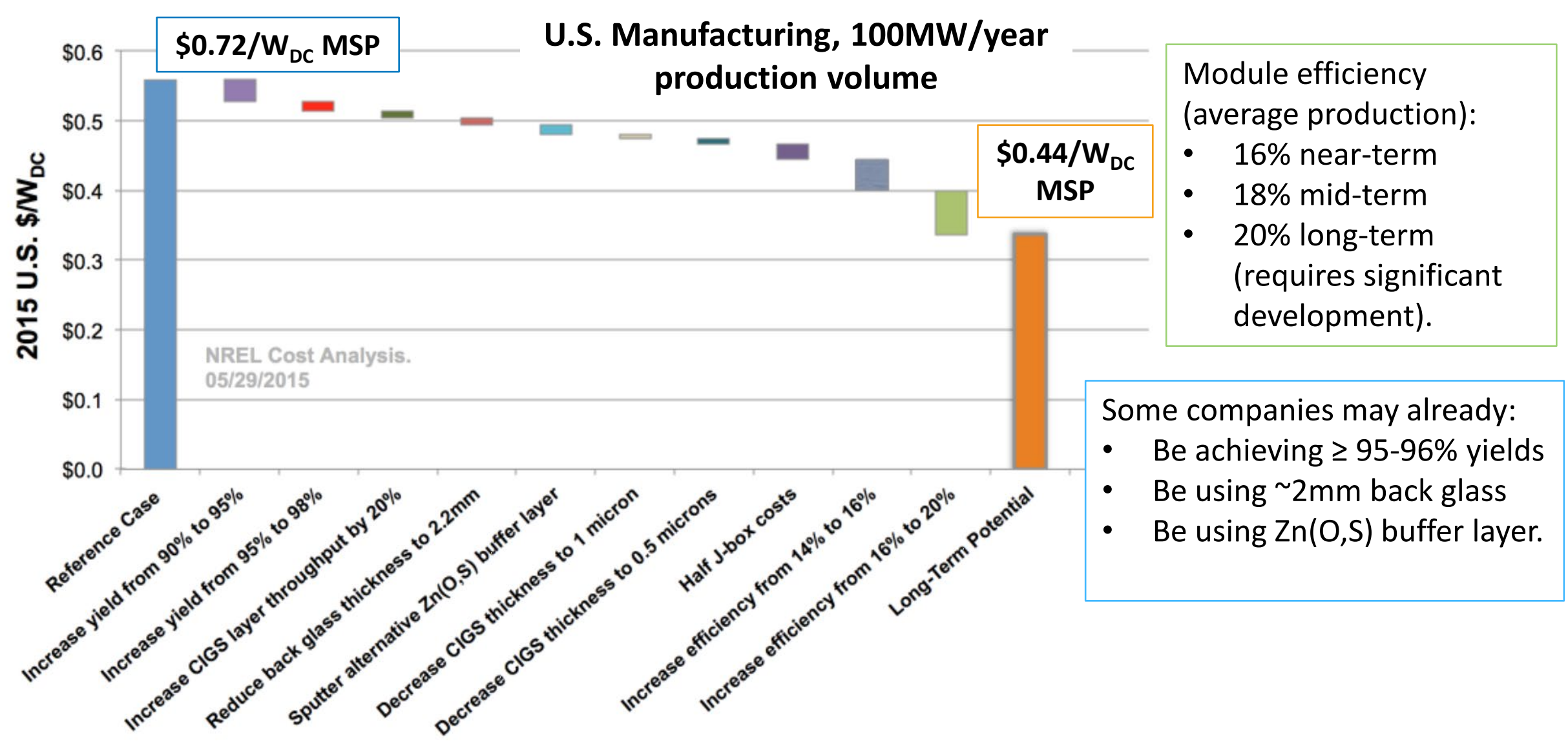

- Decreasing the thicknesses to below 1.5 microns may require engineering to maintain process repeatability, as well as light-trapping structures or electron reflectors. This is an open question.

- Additional reductions could be achieved if throughput for the CIGS absorber process could be achieved without sacrificing efficiency.

- Efficiency improvements are key to future module and system $\$ / W$ reductions. 


\section{Scale and Manufacturing Location}

- Preliminary estimates indicate that scaling from $100 \mathrm{MW} /$ year to $1 \mathrm{GW} /$ year could reduce total module costs by $\$ 0.03-\$ 0.04 / W_{D C}$.

- Manufacturing in a low-cost labor location could save an additional $\$ 0.05 / \mathrm{W}_{\mathrm{DC}}$ at the assumed level of automation in our model.

- Costs will always depend on the manufacturing location, supply chain, and specific company. 


\section{LCOE of CIGS and Standard c-Si}

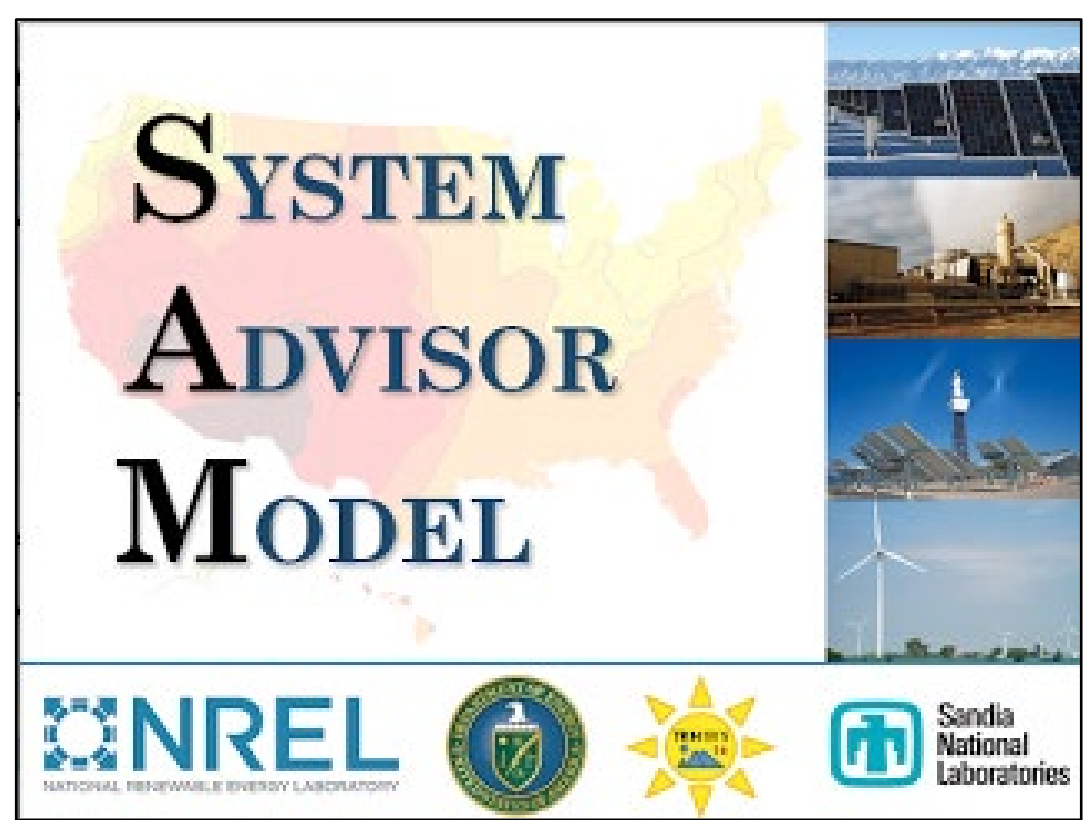

- Single-owner utility model

- $7.5 \%$ nominal discount rate, 30-year analysis period

- No state or local incentives included

- Use $\$ 0.72 / \mathrm{W}_{\mathrm{DC}}$ computed CIGS MSP for these assumptions as the module price

- $\$ 0.65 / \mathrm{W}_{\mathrm{DC}}$ used as the global C-Si module price.
TABLE II

Computed Nominal LCOEs in Phoenix, AZ

Federal ITC Level

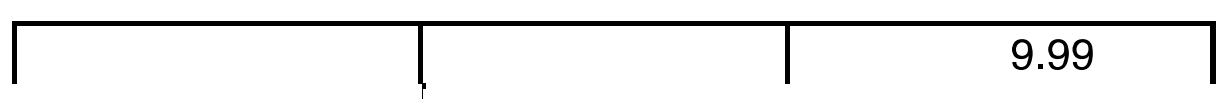

$0 \%$

- For a given system price in this climate, CIGS can achieve a lower LCOE because of the low temperature co-efficient and good lowlight performance

- Increasing module efficiency would drive down system costs, a major contributor to LCOE

- Reducing degradation rate from $-0.96 \% / y r$ assumed here to $-0.5 \% /$ year could decrease CIGS LCOE by $0.5 \mathrm{c} / \mathrm{kWh}$, depending on the module

- SAM may underestimate CIGS energy production according to industry interviews. 


\section{Summary and Future Work}

- We have built a bottom-up cost model for different CIGS manufacturing processes.

- For U.S. manufacturing and $100 \mathrm{MW} /$ year production with sputtering + batch SAS, we calculate a total module manufacturing cost of $\$ 0.59 / \mathrm{W}_{\mathrm{DC}}\left(\$ 0.72 / \mathrm{W}_{\mathrm{DC}} \mathrm{MSP}\right)$ with potential to reduce below $\$ 0.40 / \mathrm{W}_{\mathrm{DC}}$.

- Materials, balance of module, and the SAS process represent major module cost drivers.

- Using our modeled module cost numbers, we estimate the LCOE of CIGS to be close to that of standard c-Si. The difference is primarily driven by the higher system price due to the lower module efficiency (14\% vs. $16 \%)$.

- Deeper study of observed energy production in CIGS systems and energy production modeled with SAM is warranted.

- Better resolution on global material costs, supply chains, and competitiveness would provide further insight into current CIGS costs and market dynamics. 



\section{Complete LCOE Inputs}

\section{TABLE I}

InPUT AsSUmptions For LCOE CALCULATIONS

Input Parameter 